\title{
ACCURACY AND PERFORMANCE OF AUGMENTATIONS TO GLOBAL NAVIGATION SYSTEMS OUTSIDE THEIR AREAS OF COVERAGE
}

\author{
J. Stankūnas, A. Jakučionis, V. Petrusevičius
}

Antanas Gustaitis Aviation Institute, Rodūnès kelias 30, LT-02187 Vilnius-38, Lithuania.

E-mail: v.petrusevicius@gmail.com

Received 0703 2005, accepted 05122005

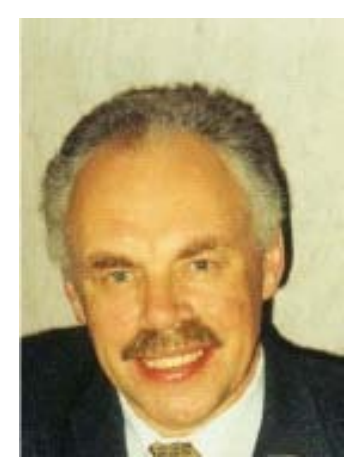

Jonas STANKUNAS, Prof Dr Habil

Date and place of birth: 1949 in Pakene, Rokiškis Distr., Lithuania.

Education: 1970 - Krivoj Rog Civil Aviation School, Ukraine; 1976 - Faculty of Automation at Vilnius Institute of Civil Engineering; 1981 -post -graduated studies at Vilnius Institute of Civil Engineering.

Affiliations and Functions: 1970 - 1972 - Aviation Technician, Vilnius Joint Aviation Platoon; 1972 - 1975 -

Expert, Radio Apparatus Technology Dept., 1975 - 1978 - Sr. Eng., Sector of Science Research; 1982 - 1987 -

Head of Science Laboratory of Slow Wave and Deflecting Systems, Vilnius Institute of Civil Engineering; 1988 1993 - Assoc Prof, Radio Apparatus Technology Department, Vilnius Technical University (formerly, Vilnius Civil Eng. Institute) and Kaunas University of Technology (formerly, Kaunas Polytechnic. Institute.). Since 1993 Director of Antanas Gustaitis Aviation Institute (AGAI) of Vilnius Gediminas Technical University; 1993 - 1995 Assoc Prof, 1995 - Habilitated Doctor; 1995 - 1997 - Prof, Air Traffic Control Department (AGAI); since 1997 Prof, Avionics Department (AGAI); since 2002 - Director of the Defense Technology Center of Vilnius Gediminas Technical University.

Awards: Laureate of Lithuanian Award in Technology Sciences, 1997.

Publications: Author or co-author of 104 scientific articles, 2 monographs, 28 reports, 97 scientific reports, and 9 education methodological publications.

Inventions: Author or co-author of 14 inventions.

Training: Advancement training in Great Britain, Canada and Sweden. 37052329 321jonas.stankunas@ai.vtu.lt; . E-mail: avinst@ai.vtu.lt; jnst@ai.vtu.lt

\section{Algimantas JAKUČIONIS, Assoc Prof Dr}

Date and place of birth: 1942 in Lithuania.

Education: Kaunas Polytechnic Institute (now Kaunas Technological University), radio electronics engineer; 1994 - specialized courses of radio navigation systems at SATSA (Sweden); 1995 - 1996 - on the scheduled base of the

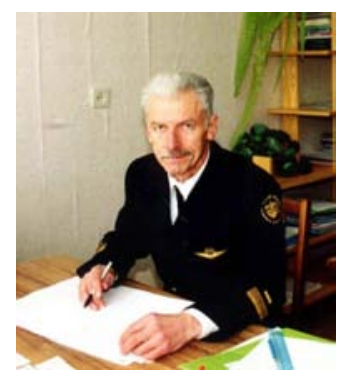
TEMPUS international project - qualification-training studies in the field of electronic navigation systems at London City University and Bologna University (Italy).

Affiliations and functions: Since 1993 - Lecturer (assoc. professor) at the Antanas Gustaitis Aviation Institute of Vilnius Gediminas Technical University; 1974 - Scientific degree of Doctor in the field of technical sciences; 1998 - Scientific pedagogical degree of Associated Professor.

Experience: 1965 - 1968 - New Types of Oscilloscopes; 1968 - 1970 - Integrated Logical Circuits; 1971 - 1974 Electromagnetic Wave Delay Devices; 1975 - 1992 - Optimization and Metrology Problems of TV Units.

Teaching: Electronics Navigation Systems Subjects.

Publications: Author of the more than 20 scientific papers, participant of national and international scientific conferences and seminars.

Present position: Head of the Department of Avionics at Antanas Gustaitis Aviation Institute of Vilnius Gediminas Technical University; Rodūnès k. 30, LT - 02187 Vilnius-38, Lithuania; Tel. 37052739028.

E-mail: algim@ai.vtu.lt

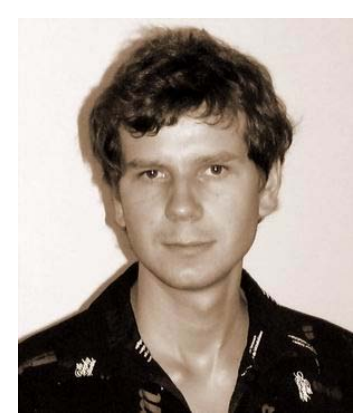

Vytis PETRUSEVIČIUS, MSc

Date and place of birth: June 1981, Klaipèda, Lithuania.

Education: 2003 - Antanas Gustaitis Aviation Institute of Vilnius Gediminas Techinical University, Bachelor's degree in Electrical Engineering.

Affiliations and functions: 2003 - assistant in the Aircraft electrical equipment laboratory of "Aviavilta" company, simultaneously studying at Antanas Gustaitis of Aviation Institute, Master of Science degree in Electrical Engineering. Since September of 2004 he has been working as an avionics engineer in the aircraft's maintenance department of State Border Guard Service.

Research interests: avionics' test techniques.

Abstract. Signals broadcasted by Global Positioning System are a good solution for aircraft navigation in remote areas where conventional ground-based navigation means do not exist. In the world of avionics, more and more navigation guidance systems based on GPS are being developed. Very high claims in terms of accuracy, reliability, and integrity are required for such systems. But GPS alone cannot satisfy these requirements. For this reason, augmentation systems have been designed, which along with GPS receivers form state-of-the-art navigation systems. 
This paper discusses existing augmentation means to GPS in Europe, their accuracy, and the possibility for aircraft flights over Lithuania to use corrections broadcasted of one or another augmentation system.

Keywords: GPS, augmentation, Euro fix, EGNOS, accuracy, spatial decorelation.

\section{Introduction}

In the Baltic States and other European countries, many small airfields that are not equipped with instrument approach facilities exist. Now existing global navigation systems enable their signals to be used for enroute and terminal areas. But neither GPS nor GLONASS alone can meet the civil aviation requirements for precision and non-precision approach phases of flight without a system augmentation.

If to restrict our attention to the Baltic region, three main augmentations of GPS exist: the first is the network of European differential beacons, the second is the Euro fix system based on the long range navigation system Loran- $\mathrm{C}$, and the third is the European Geostationary Navigation Overlay Service (EGNOS).

One of the most important characteristics of the system possibilities for guidance of aircraft in approach phase of the flight is its ability to ensure good positioning accuracy.

In this paper, we are going to discuss usage possibilities and accuracies of differential GPS signals outside areas of reference stations. We will focus on using such signals in Lithuania. We will review existing GPS augmentation systems in Europe, their general structure, and location of reference stations. In the conclusion, we decide which augmentation system is the best fit for Lithuania in terms of accuracy, and what the advantages and disadvantages of each system reviewed are.

\section{Network of European differential beacons}

Displacement of the European differential radio beacons nearest to Lithuania is depicted in Fig 1. Radio beacons transmit differential GPS corrections in almost real time on carrier frequencies of the frequency band 283.5...315 KHz [6].

The feature of propagation of middle length radio waves means that it is possible to use the corrections for instrument approach purposes with installed DGPS receiver on-board the approaching to the airfield aircraft at distances of several hundred kilometers from DGPS beacons and flight altitudes may be quite low. Differential GPS corrections are effective for ranges of about 50 kilometers from DGPS stations [7].
Transmission rates of differential GPS corrections, the carrier frequencies, and other data of some European differential beacons nearest the center of Lithuania are presented in Table 1 [3].

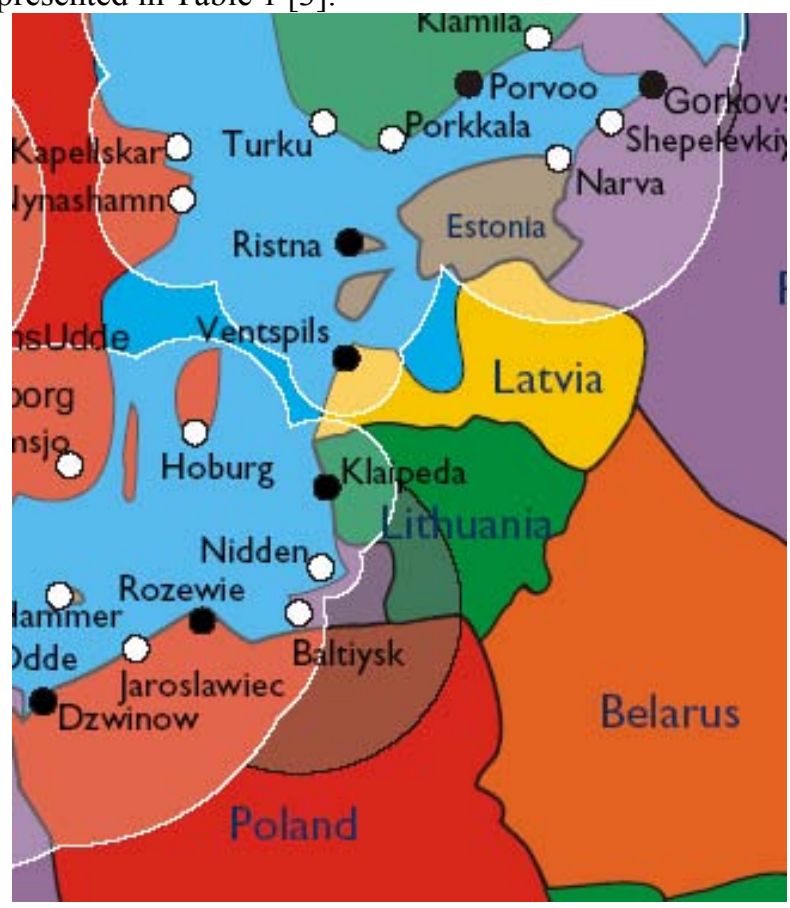

Fig 1. DGPS coverage of European Radio beacons

\section{Analysis of DGPS corrections effectiveness}

The effectiveness of DGPS corrections decreases due to spatial and time dependent decorrelation.

As the receiver of a DGPS station finds DGPS corrections at the epoch $t_{0}$ and the on-board receiver applies these corrections at the epoch $t$, the values of corrections for the on-board GPS receiver will be:

$$
\left[\Delta R^{j}(t)\right]_{c o r r .}=\Delta R_{A}^{j}\left(t_{0}\right)+\frac{\partial\left[\Delta R_{A}^{j}\left(t_{0}\right)\right]}{\partial t} \cdot\left(t-t_{0}\right)
$$

Then residual errors for pseudo ranges after applying DGPS corrections in on-board GPS receiver will be:

$$
\begin{aligned}
& {\left[\Delta R_{V}(t)\right]_{\text {corr. }}=R_{V}^{j}(t)-\rho_{V}^{j}(t)+\left[\Delta R^{j}(t)\right]_{\text {corr. }}=} \\
& =\underbrace{d \rho_{V}^{j}(t)-d \rho_{A}^{j}\left(t_{0}\right)}_{I}+\underbrace{c \cdot\left[b_{V}(t)-b_{A}\left(t_{0}\right)\right]}_{I I}+\underbrace{c \cdot\left[B^{j}(t)-B^{j}\left(t_{0}\right)\right]}_{I I I}+ \\
& +\underbrace{c \cdot\left[d_{\text {ion } V}^{j}(t)-d_{\text {ionA }}^{j}\left(t_{0}\right)\right]}_{I V}+\underbrace{c \cdot\left[d_{t r V}^{j}(t)-d_{\text {trA }}^{j}\left(t_{0}\right)\right]}_{V}+\underbrace{\left[\varepsilon_{V}(t)-\varepsilon_{A}\left(t_{0}\right)\right]}_{V I}+\underbrace{\left[\frac{\partial\left[\Delta R_{A}^{j}(t)\right]}{\partial t}\right] \cdot\left(t-t_{0}\right)}_{V I I}
\end{aligned}
$$


where $\Delta R$ - differences between geometric ranges $\rho$ and pseudo ranges, i.e., pseudo range from the station's GPS receiver to the $\mathrm{j}$-th satellite (index A) and pseudo range from on-board GPS receiver to the $\mathrm{j}$-th satellite (index V), $c$ - speed of e.m. waves; $b$ and $B$ - clock biases of the GPS receiver and satellite with respect to the GPS time scale; $d_{i o n}$ and $d_{t r}$ - satellite signal delay times in the ionosphere and troposphere, $\varepsilon$ - items to evaluate pseudo range measurement errors due to GPS receiver noise and GPS signal multipath. The first item of equation (2) means residual error of range measurement due to satellite ephemeredes errors. The second item is due to differences of time scales of onboard GPS receiver and station GPS receiver. The third item is due to change in time differences between GPS system and satellite time scale biases. The fourth and fifth items are due to the different influence of the ionosphere and troposphere respectively for signals to reference (station) and onboard GPS receivers. The sixth item is due to different noises or reference receiver and on-board GPS receiver and different multipart of GPS signals to those receivers. The seventh item estimates the quantity that may be received with the DGPS station signal and enables the rate of change of the corrections in time to be evaluated and improve corrections by estimation of its delay. The GPS system and satellite time scales are formed by very stable atomic clocks. Also, as it is known, the selective availability (S/A) function of the GPS NAVSTAR was switched off in 2000. The residual errors of the first and third items are therefore close to zero. Factors of the errors estimated by the sixth item are random and residual errors for these sources do not depend on time or distance. In the time interval $\left(t-t_{0}\right)$, which is equal for some seconds and means a delay in applying DGPS correction in the on-board receiver, quantities $d_{i o n}$ and $d_{t r}$ remain approximately the same. But they change with the change of distances between the reference DGPS station receiver and the on-board GPS receiver. For this spatial decorrelation we have:

$$
\begin{aligned}
& \Delta d_{i o n}(x) \approx \Delta d_{i o n}\left(x_{0}\right)+\frac{\partial\left(\Delta d_{i o n}\right)}{\partial x} d x \\
& \Delta d_{t r}(x) \approx \Delta d_{t r}\left(x_{0}\right)+\frac{\partial\left(\Delta d_{t r}\right)}{\partial x} d x .
\end{aligned}
$$

In the area around point $x_{0}$, which may be considered as a circle with a radius of about $50 \mathrm{~km}$, we may assume that $d_{i o n V} \approx d_{\text {ionA }}$ and $d_{t r V} \approx d_{t r A}$, which means $\Delta d_{\text {ion,tr }}\left(x_{0}\right) \approx 0$. But if we talk about aircraft routes, for example, somewhere in Lithuania, and for these flights we intend to use DGPS corrections translated by European differential beacons, let say specified in table 1 , one can see that distances from the middle Lithuania to these stations are $150-500 \mathrm{~km}$ or longer (Fig 1).

As it follows from investigations of wide area DGPS, the average values of spatial decorrelations of DGPS corrections for errors due to ionosphere and troposphere influence on GPS signals are (2-4) $\mathrm{mm} / \mathrm{km}$ for ionosphere and (1-2) $\mathrm{mm} / \mathrm{km}$ for troposphere [2]. Data illustrating how predictably accuracy changes with distance for DGPS corrections are shown in Table 2.

As one can see, using a GPS signal with transmissions from European DGPS stations for flights in Lithuania will not give acceptable accuracy (usually expressed as $2 \cdot \delta$ ) for aircraft in precision approach and landing phases.

\section{Possibilities of usage of Euro fix network}

Loran-C stations of the Northwest European LORAN-C System (NELS) (Fig 2a), the former Mediterranean Sea Chain (Fig 2b), and the European Chayka Chain (Fig 2c) equipped with the Euro fix technique form a system of local area GNSS augmentation stations $[4,8,1]$.

As one can see from Fig 2, most chain stations that play a role as Euro fix network stations transmitting DGPS corrections are at distances of several hundred or even more than $1000 \mathrm{~km}$ from the centre of Lithuania. From the analysis of the effectiveness of DGPS corrections in the earlier section of this paper, the conclusion follows that the effectiveness of DGPS corrections from Euro fix will be the same as for the differential DGPS beacon network or will be even bigger. For the purpose of the improvement of these corrections, the user has to use Euro fix as a regional area augmentation system (RAAS) instead of using it as LAAS [4]. RAAS mode requires two or more Euro fix stations within range. The user may then operate in a quasi network mode by applying the weighted average of the received corrections from the multiple stations. RAAS is very interesting since it offers even better accuracy and reliability than the single-station LAAS mode of operation.

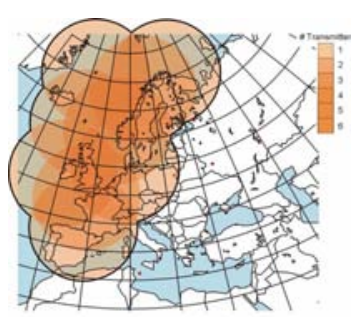

a)

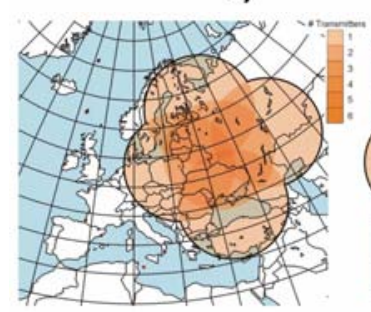

c)

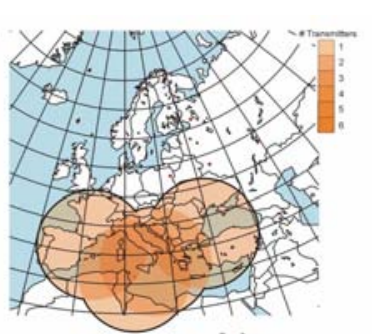

b)

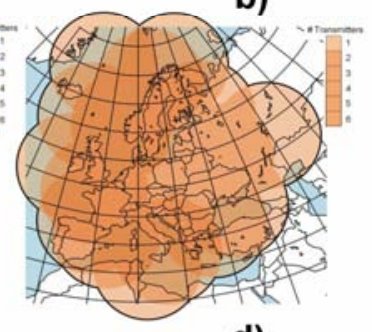

d)
Fig 2. Euro fix coverage: NELS stations (a); Mediterranean Sea Chain stations (b); Chayka stations (c); resulting coverage (d) 
Table 1. Data of some European differential beacons nearest the center of Lithuania

\begin{tabular}{|c||l||c||c||l|}
\hline $\begin{array}{c}\text { Reference } \\
\text { ID }\end{array}$ & $\begin{array}{c}\text { Broadcast } \\
\text { Site }\end{array}$ & $\begin{array}{c}\text { Carrier frequency } \\
\text { KHz }\end{array}$ & $\begin{array}{c}\text { MSK } \\
\text { (bps) }\end{array}$ & \multicolumn{1}{|c|}{ Status } \\
\hline \hline 481 & Dziwnów & 283.5 & 100 & online \\
\hline 483 & Jaroslawiec & 295.0 & 100 & proposed \\
\hline 482 & Rozewie & 301.0 & 100 & online \\
\hline 001 & Baltiysk & 286.5 & 100 & proposed \\
\hline- & Nidden & 315.5 & - & proposed \\
\hline 535 & Klaipeda & 304.5 & 200 & online \\
\hline- & Ventspils & 308.5 & - & online \\
\hline 530 & Ristna & 307.0 & 200 & online \\
\hline 465 & Hoburg & 297.5 & 100 & online \\
\hline
\end{tabular}

Table 2. Data illustrating how predictably accuracy changes with distance for DGPS corrections

\begin{tabular}{|c|c|c|c|c|c|c|}
\hline \multirow{3}{*}{$\begin{array}{c}\text { Sources of } \\
\text { errors }\end{array}$} & \multicolumn{6}{|c|}{ Range error $(1 \cdot \delta) \mathrm{m}$} \\
\hline & \multirow{2}{*}{$\begin{array}{l}\text { without } \\
\text { correction }\end{array}$} & \multicolumn{5}{|c|}{$\begin{array}{l}\text { residual errors after applying DGPS corrections with Potency }<5 \text { s when distance between } \\
\text { onboard GPS receiver and DGPS station is }[\mathrm{km}]\end{array}$} \\
\hline & & $<50$ & 100 & $200 \ldots 250$ & $360 \ldots 400$ & 500 \\
\hline $\begin{array}{l}\text { Ephemerid } \\
\text { errors }\end{array}$ & $6 \ldots 10$ & $<0.5$ & $<0.5$ & 0.5 & 0.6 & 0.6 \\
\hline Ionosphere & $2 \ldots 10$ & $<0.1$ & $<0.4$ & 0.8 & 1.5 & 2.0 \\
\hline Troposphere & $1 \ldots 2$ & $<0.1$ & $<0.2$ & 0.5 & 0.7 & 1.0 \\
\hline Multipath & 1.4 & $0.2-1$ & $0.2-1$ & $0.2-1$ & $0.2-1$ & $0.2-1$ \\
\hline $\begin{array}{l}\text { Receiver } \\
\text { noise and } \\
\text { other } \\
\text { receiver } \\
\text { errors }\end{array}$ & 0.5 & 0.5 & 0.5 & 0.5 & 0.5 & 0.5 \\
\hline $\begin{array}{l}\text { Reference } \\
\text { station } \\
\text { errors } \\
\end{array}$ & 0 & 0.2 & 0.2 & 0.2 & 0.2 & 0.2 \\
\hline $\begin{array}{l}\text { Equivalent } \\
\text { r.m.s. }(1 ・ \\
\delta), \mathrm{m}\end{array}$ & $6.6-14.3$ & $0.8-1.3$ & $0.9-1.33$ & $1.22-1.6$ & $1.86-2.1$ & $2.4-2.6$ \\
\hline $\begin{array}{l}\text { Equivalent } \\
\text { position } \\
\text { error } \\
\left(\mathrm{G}_{\mathrm{H}}=2\right)\end{array}$ & 20 & 2.6 & 2.7 & 3.2 & 4.2 & 5.2 \\
\hline $\begin{array}{l}\text { Equivalent } \\
\text { vertical } \\
\text { error } \\
\left(\mathrm{G}_{\mathrm{V}}=2,5\right)\end{array}$ & 30 & 3.25 & 3.3 & 4.0 & 5.25 & 6.5 \\
\hline
\end{tabular}

$\mathrm{G}_{\mathrm{H}}$ and $\mathrm{G}_{\mathrm{V}}-$ satellite position geometry factors

\section{European Geostationary Navigation Overlay Service (EGNOS)}

The purpose of EGNOS is to implement a system that fulfils a range of user service requirements by means of an overlay augmentation to GPS and GLONASS based on the broadcasting through GEO satellites of GPS-like navigation signals containing integrity and differential correction information applicable to the navigation signals of the GPS satellites, the GLONASS satellites, EGNOS GEO Overlay satellites, and the signals of other GEO Overlay systems (provided they can be received by a GNSS-1 user located inside the defined EGNOS service area) $[9,5,10]$.

The EGNOS architecture is composed of four segments: ground segment, space segment, user segment, and support facilities.

The EGNOS Ground Segment consists of GNSS (GPS, GLONASS, GEO) ranging and integrity monitoring stations (called RIMS) that are connected to a set of redundant control and processing facilities called Mission Control Centre (MCC). The system will deploy 34 RIMS located mainly in Europe and four MCCs. The MCCs determine the integrity and pseudo-range differential corrections for each monitored satellite, 
ionosphere delays and generates GEO satellite ephemeris. This information is sent in a message to the Navigation Land Earth Station (NLES), to be up-linked along with the GEO Ranging Signal to GEO satellites. These GEO satellites downlink this data on the GPS Link 1 (L1) frequency with a modulation and coding scheme similar to the GPS alone. (Fig 3 shows planned sites for the different EGNOS G/S elements).

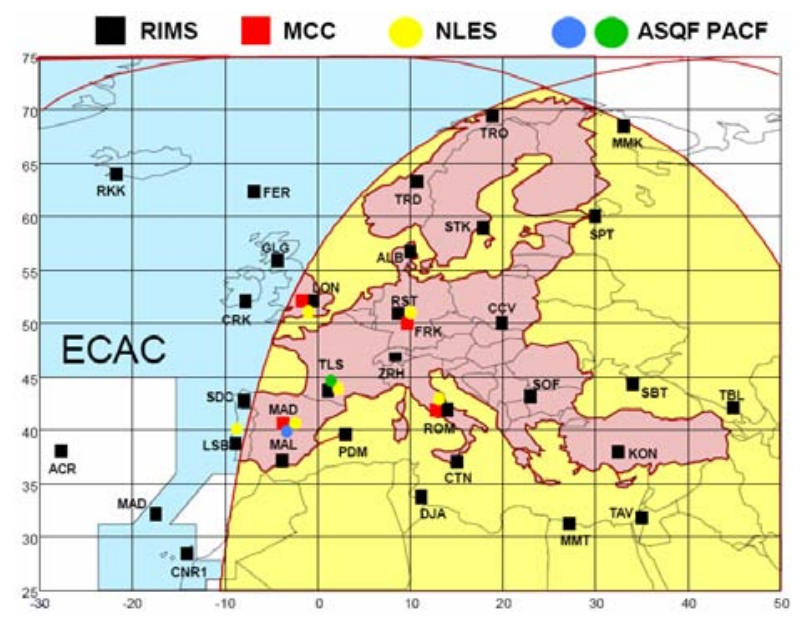

Fig 3. EGNOS deployment map

Before EGNOS becomes fully operational, airline pilots and others equipped with an EGNOS receiver can tune in to a test signal broadcast by the ESTB [5]. The ESTB (EGNOS System Test Bed) is a real-time prototype of EGNOS. Test signal broadcasting began in February 2000 via Inmarsat AOR-E (Atlantic Ocean Region - East) and today is broadcast via Inmarsat IOR (Indian Ocean Region). At present, ESTB consists of 10 ranging integrity monitoring stations (RIMS) dotted about Europe - this number may increase once the MTB is connected to ESTB - and one processing centre that collects data for modulation onto the EGNOS signal.

The architecture of ESTB is presented in Fig 4.

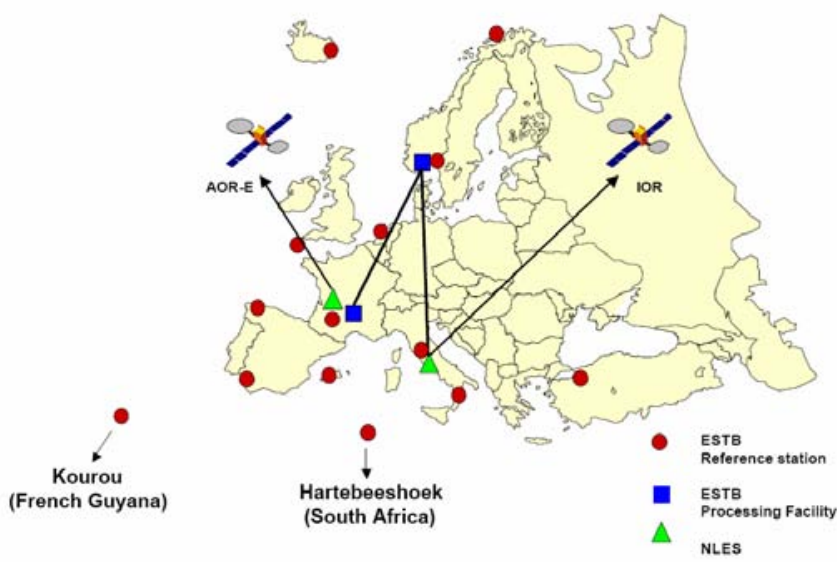

Fig 4. Architecture of the EGNOS System Test Bed (ESTB)

By using GPS and ESTB Signal-In-Space, users in Europe can nowadays determine their position with submeter errors both in horizontal and vertical components
95 percent of the time [9]. This is illustrated in Figure 5, which is based on real-data collected from the ESTB. The area within the test signal that can be exploited is determined primarily by the location of the reference stations. The ESTB APV-2 service area is depicted in Figure 6 (this figure is also based on real data collected from the system).

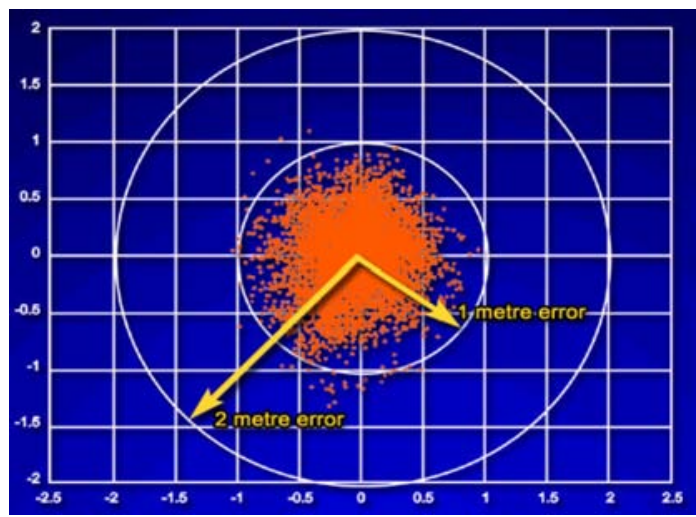

Fig 5. Typical ESTB performances: sub-meter Horizontal $(95 \%)$ and Vertical $(95 \%)$ accuracies
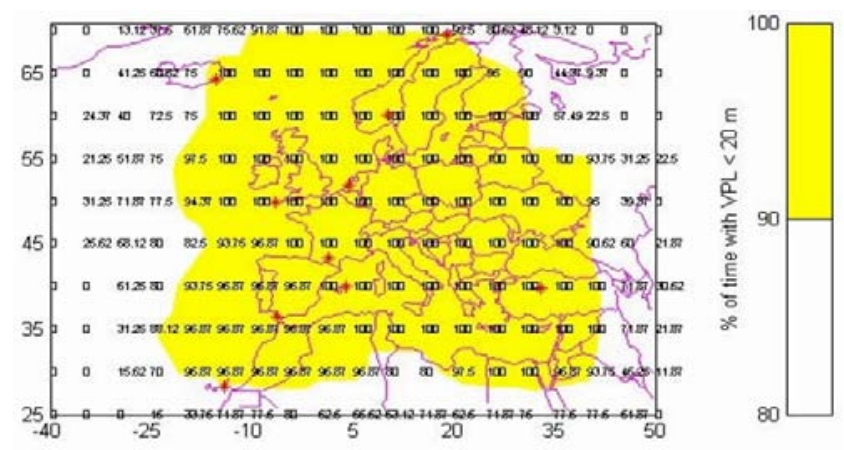

Fig 6. ESTB APV-2 service area (based on real data)

Though the ESTB service area fully covers the territory of Lithuania, positioning errors using this service in our country will not be the same as those depicted in Fig 5. This follows from an analysis of the effectiveness of DGPS corrections. Lithuania is far away from the nearest ESTB reference station.

\section{Conclusions}

Usage of satellite-based navigation aids and their augmentations for aircraft flights in Lithuania were discussed.

Since European differential beacons were initially intended for marine application, most of these beacons are situated on coastal territories, and there is a lack of beacons for overland routes. The conclusion follows that, using such a service for navigation inside the country, positioning errors due to spatial decorrelation increase along with the increasing distance between the user and differential beacon.

Even using Euro fix as regional area augmentation system its accuracy is similar to DGNSS and therefore does not offer any immediately apparent direct 
operational benefits beyond those available from the other systems. Due to the fact that Euro fix uses the Loran-C signal as a carrier, the future of Euro fix depends on the future of Loran-C itself.

Since signals broadcasted by the EGNOS system have frequency, modulation, and coding schemes similar to the ones that GPS has, it would be acceptable to use such a system for aircraft navigation and non-precision approach. Furthermore the accuracy of the signals of the EGNOS system will increase in the future with the completion and development of this system.

To gain the highest positioning accuracy today for aircraft flights inside Lithuania, we should choose the network of European differential beacons as augmentation to GPS. This is because this network has a beacon nearest to the center of Lithuania.

\section{References}

1. Argunov A.D., Bass V.J. et al. Perspectives of Developing the Russian Radio navigation System "Chayka" // Materials of International conference - "Navigation - 2000". - 2000.

2. Christie Jock R., et al. Analytical and Experimental Observations on Ionosphere and Troposphere Decorrelation Effects for Differential Satellite Navigation during Precision Approach // Proceedings of ION GPS. - Nashville, 1998 September.

3. DGPS Radio Beacon Listing. CSI Wireless Inc. 2004 // www.csi-

wireless.com/support/pdfs/radiolistings.pdf
4. Forst Ch. Information on EUROFIX. - Euripi working group, 1998.

5. EGNOS for Professionals // http://esamultimedia.esa.int/docs/egnos/estb/egn os_pro.htm

6. Hoppe M. Evaluation of Existing and Emerging Positioning Technologies. - Letzte Änderung: Fachstelle der WSV für Verkehrstechniken, 2004.

7. Hoffman-Wellenhof B., Lichtenegger H., Collins J. GPS - Theory and Practice- New York: Springer - Verlag Wien, 1992. $/ 2^{\text {nd }}$ Edition.

8. Norvald K. The Role of Loran $-\mathrm{C}$ in Present and Future Navigation from a Norwegian Nautical Perspective // The Journal of Navigation. - 2002. - No 55. - P. 185-195.

9. Toran-Marti F., Ventura-Travest J. The ESA EGNOS Project: The First Step of the European Contribution to the Global Navigation Satellite System (GNSS). - Toulouse: GNSS-1 Project Office. European Space Agency (ESA), 2004.

10. Ventura-Traveset J., et al. Architecture, mission and signal processing aspects of the EGNOS System: The first European implementation of GNSS. - Toulouse Cedex: European Space Agency (ESA). 